\title{
1 Is there a rural penalty in language acquisition? Evidence from 2 Germany's refugee allocation policy
}

\section{Abstract}

6 Emerging evidence has highlighted the important role of local contexts on integration trajectories of 7 asylum seekers and refugees. Germany's policy of randomly allocating asylum seekers across 8 Germany may advantage some and disadvantage others in terms of opportunities for equal participation 9 in society. This study explores the question whether asylum seekers that have been allocated to rural 10 areas experience disadvantages in terms of language acquisition compared to those allocated to urban 11 areas. We derive testable assumptions using a Directed Acyclic Graph (DAG) which are then tested 12 using large-N survey data (IAB-BAMF-SOEP refugee survey). We find that living in a rural area has

13 no negative total effect on language skills. Further the findings suggest that the 'null effect' is the result 14 of two processes which offset each other: while asylum seekers in rural areas have slightly lower access 15 for formal, federally organized language courses, they have more regular exposure to German speakers.

17 Keywords: refugees, asylum seeker, language, policy, rural, contacts, integration 
20 Once asylum seekers arrive in Germany, they are distributed geographically across the German regions. The number of asylum seekers that each region receives is based on a quota system considering tax returns and population size in each region (Königstein key). The allocation of individuals across those defined regions occurs randomly. This policy is subject to much debate. The system resembles a lottery that may produce winners and losers. An emerging body of research suggests that the initial placement of asylum seekers shapes their further integration trajectories into society (Barry R. Chiswick and Paul W. Miller 2002; Åslund and Rooth 2007; Aksoy, Poutvaara, and Schikora 2020). Local contexts may vary substantially in terms of educational, labor market and social opportunities they provide for migrants (Godøy 2017; Martén, Hainmueller, and Hangartner 2019; Braun and Dwenger 2020; Edin, Fredriksson, and Aslund 2003; Beaman 2012). Several initiatives have been launched to assess the potential of taking additional characteristics into account when matching asylum seekers to localities with the aim to increase integration outcomes such as employment (Bansak et al. 2018). ${ }^{1}$ The societal benefits of improving geographic assignment appear large in light of the long-term disadvantage that asylum seekers and refugees face in terms of employment and earnings (Brücker, Jaschke, and Kosyakova 2019; Brell, Dustmann, and Preston 2020).

In this study, we aim to explore the question whether asylum seekers that have been allocated to rural areas experience disadvantages compared to those allocated to urban areas. Some studies have shown that urban centers with a higher share of co-ethnic residents provide advantages in term of economic integration (Martén, Hainmueller, and Hangartner 2019). Higher concentration of co-ethnic networks reduce initial language barriers and information asymmetries when searching jobs. Urban areas may also provide more support to newcomers in terms of language learning opportunities or other support services in multiple languages. Rural areas - due to fewer available resources and fewer previous migration - may offer less support. Several initiatives have been launched in Germany to improve access to integration courses (providing language learning opportunities) in rural areas (Rösch et al. 2020; Fachkommission Integrationsfähigkeit 2021; Ohlinger and Schweiger 2019). Research on coethnic networks and integration opportunity structures suggest that asylum seekers could be

${ }^{1}$ In collaboration with individual German regions (Bundeslaender), researchers from the University of Hildesheim and the Friedrich-Alexander-Universität Erlangen-Nürnberg are currently developing an ,algorithm-based' mechanism to distribute refugees to districts (see www.matchin-project.de) 


\section{Is there a rural penalty in language acquisition?}

47 disadvantaged in rural areas. The available empirical evidence, however, is still limited (Rösch et al. 48 2020).

49 In this study, we explore potential rural penalties with a focus on language acquisition. Language skills 50 are often highlighted as the main driver of positive integration trajectories (Kosyakova, Kristen, and 51 Spörlein 2021; Esser 2006; Kristen, Mühlau, and Schacht 2016) as they facilitate job searches, social 52 integration, and correspondence with authorities or navigation of host-country institutions (Alba, 53 Sloan, and Sperling 2011; Espenshade and Fu 1997; Martinovic, F. van Tubergen, and Maas 2009). In 54 particular, we will assess several pathways that may explain differences in language acquisition between rural and urban locations based on a casual model illustrated by Directed Acyclic Graphs (DAG) (Elwert 2013). We derive testable hypotheses based on language learning models initially developed by Chiswick and Miller (2001) and later extended and applied by various authors (e.g. Kristen, Mühlau, and Schacht 2016; Kosyakova, Kristen, and Spörlein 2021).

Based on large survey data in Germany (SOEP IAB-BAMF refugee sample; $\mathrm{N}=13,187$ ), we first test whether there is, indeed, a rural penalty in language acquisition of asylum seekers. Second, we explore whether potential urban-rural disparities are related to differences in social networks (i.e. exposure to German speakers) and learning opportunities (access to language courses). Research has shown that contacts with natives (Danzer and Yaman 2013; Heath, Rothon, and Kilpi 2008; Bauer, Epstein, and Gang 2005) and participation in language courses (Auer 2018; Vroome and Frank van Tubergen 2010; Arendt et al. 2020; Kosyakova and Brenzel 2020; Kaida 2013; Clausen et al. 2009; Lochmann, Rapoport, and Speciale 2019; Sarvimäki and Hämäläinen 2016; Hoehne and Michalowski 2016; F. van Tubergen 2010) have strong and lasting effects on integration outcomes such as language acquisition and employment.

While previous research has largely discussed individual mechanisms in isolation, we propose a broader framework that incorporates different forms of opportunity structures for language acquisition of refugees depending on their geographic location. The geographic dimension of integration of refugees was neglected previously, largely due to the lack of suitable data sources. There is ongoing discussion on how particular contexts shape integration outcomes for example with respect to concentration of co-ethnic/ migrant networks, contacts to non-migrants, local employment rates, and state-funded integration support initiatives. 
76 Our results show that (1) there is no overall rural penalty in refugees' language acquisition in Germany,

77 (2) both contact with Germans and participation in different forms of language courses proof to be

78 highly effective in increasing refugees' language acquisition and (3) intergroup contact with Germans

79 is significantly more likely in rural areas while official course participations are somewhat less likely.

80 Overall, it can be concluded that language learning in rural areas runs to a greater extent via contacts

81 with Germans, while in urban areas institutional services are a more relevant factor.

82 In addition to advancing understanding of how local contexts shape integration of refugees, these 83 results have implications for policy. The federal government is responsible for the allocation of 84 refugees across regions and regional authorities are responsible for allocation of refugees to districts. 85 The findings reject the claim that refugees are disadvantaged in rural areas in terms of language 86 acquisition, partly because higher expose to German speakers offsets marginally lower access to formal 87 language courses. The results also suggest that further investment in courses in rural areas and more 88 opportunities for interactions with Germans in urban areas could accelerate language acquisition of 89 refugees and thus maximize integration benefits for refugees and society.

\section{$92 \quad 2 \quad$ Theory}

93 According to the Chiswick-Miller language learning model, host-country language acquisition is a

94 function of efficiency, incentives and exposure (B. R. Chiswick and P. W. Miller 2001). Efficiency

95 captures factors that facilitate individual language learning such as prior education attainment, young 96 age, and cognitive skills. Incentives reflect the motivation of the language learner and are driven by 97 expected economic (i.e., income) and non-economic (home-country attachment, social exclusion) 98 returns. The incentive dimension incorporates costs associated with language learning such as fees for 99 instruction, material costs or opportunity costs associated with delayed transition to gainful 100 employment. Incentives are commonly modelled as a (rational) cost-benefit calculation by the 101 individual migrant.

102 Exposure - the main dimension of interest for this study - refers to "the degree to which the new 103 language is present in contexts that immigrants encounter” (Kosyakova, Kristen, and Spörlein 2021, 


\section{Is there a rural penalty in language acquisition?}

104 4). Exposure incorporates structural language learning opportunities such as courses and interactions with native-speakers.

106 In this study, we are interested in potential disadvantages of residing in a rural area with regards to

107 language learning among recently arrived asylum seekers. In particular, we are interested how exposure

108 to German native-speakers (through every-day interactions) and access to formal language courses mediate potential effects of location on language learning.

110 In the following, we put forward our theoretical arguments formalized by the means of Directed

111 Acyclic Graphs (DAGs). DAGs are a tool to illustrate the causal model, make assumptions transparent 112 and derive formal rules for selecting control variables (Elwert 2013; Morgan and Winship 2014).

116 The main interest of this study is the total causal effect of location (urban vs. rural) on language 117 acquisition (in the form of skills) (see Figure 1). More explicitly, we are interested in the role of in the 118 two indirect effects of courses (M2) and contacts to Germans (M1).

119 We assume that there is a negative total effect of a rural location, i.e. 'rural penalty'. There are several 120 reasons to assume this relationship: First, rural communities often provide less assistance in language 121 learning. Rural communities have fewer resources to fund language learning opportunities (Schader 122 Stiftung 2011, 36; Ohlinger and Schweiger 2019; Scheible and Schneider 2020). Second, even if 123 resources are available, rural areas do not benefit from scaling effects due to lower population size and 124 density. In other words, if fewer asylum seekers are present, certain investments in support measures 125 such as integration courses may not be deemed cost-effective (Scheible and Schneider 2020; Ohlinger 126 and Schweiger 2019). Third, rural areas have lower levels of previous migration which indicated less 127 experience with managing diversity and established support policies (Rösch et al. 2020). This could 128 mean that available support is of lower quality or consistency. Fourth, courses may be available in 129 neighboring localities but too difficult to access given the distance and lower public transport provision 130 (Scheible and Schneider 2020). Fifth, migrants in rural areas may be less incentivized to learn the 131 languages because there are lower expected returns to the investment given that fewer and worse jobs 
132 are available in rural areas compares to urban areas. Therefore, net of relevant confounding individual-

133 level characteristics, we assume that part of the rural penalty in language acquisition is mediated by

134 lower access to language course opportunities (see path 2 and 5, X -> M2 -> Y).

135

136 In contrast, we assume that asylum seekers in rural areas may have more exposure to German native-

137 speaker simply because the group of co-ethnics is likely smaller as fewer asylum seekers are allocated

138 to smaller places (see path 3 and 4, $\mathbf{X} \rightarrow \mathbf{M 1} \rightarrow \mathbf{Y}$ ). Allocation in Germany is partially based on

139 population size. In Germany, the percentage of individuals with a migrant background is concentrated

140 in urban or suburban areas (Beauftragte der Bundesregierung für Migration, Flüchtlinge und

141 Integration 2021, 43-44). Asylum seekers in urban contexts rely on co-ethnic networks for information

142 and support. Where this may have positive effects for employment and navigating host-country society,

143 it may be a disadvantage in terms of language learning because interaction with native speakers is less

144 inevitable (Danzer and Yaman 2013; Bauer, Epstein, and Gang 2005; Kanas et al. 2012;

145 Barry R. Chiswick and Paul W. Miller 2002; B. R. Chiswick and P. W. Miller 1996; Chiswick, B. R., 146 \& Wang, Z. 2019).

148 Previous literature has shown that participation in language courses and exposure to native-speakers 149 has positive effects on learning the host-country language (path 4 and 5) (see intro for references). We 150 argue that access to those opportunities differs by the type of community that asylum seekers are 151 assigned to.

153 An obvious contention that may threaten the causal interpretation of our findings is selection. Asylum 154 seekers with particular (observable or unobservable) characteristics may be more likely to live in rural 155 areas (Rösch et al. 2020). The same characteristics may be associated with better access to integration 156 courses and interactions with Germany $(\mathbf{Z 1})$. For example, younger and more educated migrants may 157 sort themselves into urban contexts to seek better employment and more attractive lifestyle 158 opportunities. Parents with children may prefer rural areas with lower living costs and cheaper rents 159 while parents, particularly women, have less availability to participate in language courses (Tissot et 160 al. 2019). Certain asylum seekers from countries with low recognition rates facing legal obstacles to 161 enter formal language courses could be concentrated in certain locations in Germany. 


\section{Is there a rural penalty in language acquisition?}

162 To overcome this problem, we make use of a unique feature of the German asylum seeker distribution 163 system (sometimes referred to as settlement policy in other countries). In Germany, asylum seekers are 164 randomly allocated to a particular region and then quasi-randomly distributed further to counties. No 165 information about the individual asylum seekers is considered when assigning a location. This is an 166 ideal situation for causal identification resembling a natural experiment. In addition, according to a new policy, the residence of recent asylum seekers is limited to their place of first assignment. This mobility limitation assures that the composition of asylum seekers is similar across localities which in theory - should also render the population assigned to rural and urban areas non-selective. For any potential imperfections of this random assignment that may occur in practice, we additionally control for possible confounders (including sex, age, education, number of children, country of birth, years since immigration, legal status, and partnership status). To adjust for sorting within Germany, we control for whether asylum seekers moved in any given year during the observation period.

174 Lastly, it is reasonable to expect a path between M2 and M1, and vis versa. Asylum seekers who 175 participate in courses and improve their language skills may find it easier to interact more regularly with Germany. In turn, asylum seekers who befriend Germans or who receive support from volunteers may be assisted in accessing language courses. As a result, we adjust for exposure to Germany when estimating the effect of courses on language acquisition (path 5) and for participation in language courses when estimating the effect of exposure to Germans on language acquisition (path 5).

182 In sum, we suggest that contacts to Germans and access to formal integration courses partially explain any effect from rural location on language acquisition. In fact, in rural areas, more exposure to Germans may offset any disadvantage from lower access to course. Hence, it is entirely possible that we find no

185 evidence of a rural penalty in language learning due to this compensation effect between contacts and courses.

188 Based on these theoretical reflections, we expect the following potential effects of rural area on 189 language acquisition: 
191 1) Rural penalty: A) Asylum seekers and refugees in rural areas are disadvantaged in terms of

192 language acquisition because they have lower access to formal language courses. B) Language

193 courses, in turn, have a positive effect on language acquisition.

2) Rural premium: A) Asylum seekers and refugees in rural areas have more exposure to German speakers. B) Interaction with German speakers has a positive effect on language acquisition.

3) Compensation effect: Being assigned to a rural location has no overall effect on language acquisition because the negative effect of lower access to courses (relative to urban areas) and the positive effect of exposure to native-speakers (relative to urban areas) offset each other.

\section{Data \& Methods}

\section{$204 \quad 3.1$ The IAB-BAMF-SOEP Refugee Survey}

205 The IAB-BAMF-SOEP Refugee Survey is a longitudinal household survey of asylum seekers and 206 refugees in Germany and was launched in 2016 (Liebig et al. 2021; Brücker, Rother, and Schupp 2017). The target participants entered Germany between January 2013 and June 2019 and applied for asylum. The survey covers the respondent and all household members of the respondent. The survey aims to collect information on the living conditions of protection seekers in Germany. This includes among other things information on language acquisition, schooling and vocational training, psychological and social factors as well as participation in the labor market. For this study, the rich information regarding the use of language courses is particularly relevant, as well as the information regarding different forms of intergroup contacts with Germans. To ensure that a possible lack of German skills did not pose a hurdle in responding to the survey, respondents were offered a choice of six more language versions of the questionnaire (Arabic, Kurmanji, Farsi, Urdu, Pashto and English) (Brücker, Rother, and Schupp 2017, 22).

217 For our analyses, we use all available survey-years between 2016 and 2019. From originally 18,342

218 person-survey-years, we make use of 13,187 observations that contain our variables of interest.

219 Overall, observations are nested within 6,985 individuals surveyed once or repeatedly between 2016 220 and 2019. 


\section{Is there a rural penalty in language acquisition?}

\subsection{Measurements}

222 Our main dependent variable is language proficiency in German for which we use respondents' self-

223 assessment: across three separate items, individuals are asked how well they can speak, write, and read 224 in German, each on a 5-point scale from not at all to very well (SOEP Group 2020). We use all three 225 variables to create an additive index which we allow to vary between 0 and 1 with greater values 226 indicating higher levels of language proficiency (for a similar approach, see Kosyakova, Kristen, and Spörlein 2021). To test the robustness of this measure, we also re-estimate the main models using the interviewer's assessment of the respondents' language ability. Results are discussed in section 4 and Figures available in the supplementary materials.

230 Our central independent variable captures whether refugees live in rural areas at the time of their interview. A typification of rural areas can vary greatly depending on the underlying social, economic and spatial indicators (Küpper 2020). To operationalize what we call "rural penalty", we need to distinguish contexts which likely have a low population density, fewer resources, lower access to public transportation, fewer language courses and lower concentration of inter-ethnic communities that arrived previously. Therefore, we use a typification of the Federal Institute for Research on Building, Urban Affairs and Spatial Development, exhausting variation across the more than 10,000 municipalities in Germany, providing a very fine resolution. Municipalities are classified in a nested manner within counties (core cities, dense counties and rural counties) and more general regional types (agglomeration areas, urbanized spaces and rural spaces), see Figure 2. While the two highest levels are classified primarily based on population density, there is a differentiation implemented on the lowest level of municipalities, indicating whether a given municipality represents a so-called regional center or not (Oberzentrum or Mittelzentrum). Regional centers have a supraregional significance and are usually characterized by a higher level of facilities in various areas, such as culture and education, health, transport connections or administration and authorities (Einig 2015). In principle, we define rurality when refugees do not live in such regional centers. We partly deviate from this definition in highly dense agglomeration areas, since a good accessibility of centers can be assumed, as well as we present as compared to urban areas. 
252 The two main mediating variables in our model are 'contact to Germans' and 'participation in language 253 courses'. We measure contact with Germans based on the SOEP's question on how often respondents 254 spend time with German people (SOEP Group 2020, 90). The original 6-point-scale runs from "never" 255 to "every week". We define a dummy variable indicating the top-2 values "several times per week" or 256 "every day" and contrasting them to remaining options of "every week" or less often. To test the robustness of these measures, we also re-estimate the main models using alternative measures of contacts with friends, colleagues and neighbors (see section 4.2).

Participation in language courses is measured based on several SOEP survey items regarding participation in various different types of courses. This includes the general official language course, organized by the Federal Office for Migration and Refugees ${ }^{2}$ (BAMF) as well as various specific centrally organized course formats, for instance targeted at young refugees, female refugees or with focus on occupational language development (SOEP Group 2020). We include three separate variables to compare possible differences across regions: (1) we include a variable indicating any course visit irrespective of the specific form, (2) we include a variable indicating the official (BAMF) course visit and (3) one variable indicating the report of "other" course visits which were not administered by the BAMF. The latter could therefore include locally organized efforts to promote the language acquisition of refugees and are therefore of particular importance.

To isolate the effect pathways from possible confounders, we include a set of control variables. Thus, we include information on socio-demographic factors sex, age and educational levels, migrationspecific factors country of origin, years since immigration and legal status, as well as indications on partnerships, number of children and moves since the last survey.

\section{$273 \quad 3.3 \quad$ Empirical Strategy}

274 In absence of panel data or quasi-experimental designs, our identification of the total causal effects 275 (paths 2 to 5 in Figure 1) relies on the adjustment of observed covariates based on the theoretical 276 assumptions shown in the DAG (Figure 1). We estimate each path separately. Each of the parameters of interest is estimated by respecting the backdoor criterion (Elwert 2013). That is to say, we adjust for

\footnotetext{
${ }^{2}$ Within the observation window between 2016 and 2019, there were 176 to 340 thousand annual course starters, making this course form by far the most frequent one in Germany Bundesamt für Migration und Flüchtlinge 2021.
} 


\section{Is there a rural penalty in language acquisition?}

$278 \mathrm{Z} 1$ in the estimation of paths 2 and 3, for Z1 and X in the estimation of path 5, for Z1, X and M1 for

279 the estimation of path 5 and $\mathrm{Z} 1, \mathrm{X}$ and M2 for the estimation of path 4 (see Figure 1).

280 To estimate the treatment effects of all five hypothesized paths, we use Stata's teffect command using 281 the regression adjustment (RA) estimator (StataCorp 2021). RA estimators implement a two-step 282 approach in which separated regression models of the outcome on a set of covariates are fitted for each treatment level. Using the coefficients of these separated regressions, the predicted values of the outcomes are calculated, including the out-of-sample predictions for the observations with the other treatment level(s). Each set of predicted values are than considered as the potential outcome for the respective treatment level, and the difference in the sample means of a pair or potential outcomes are taken as estimate for the corresponding population average treatment effect (StataCorp 2021; Cattaneo 2010). In comparison to standard multiple regression, this approach does not assume homogeneous treatment effects across levels of covariates. To allow for intra-individual correlation of standard errors, they are clustered on respondent-level.

As described in the previous section, for pathways 4 (contact $\rightarrow$ language acquisition) and 5 (course visit $\rightarrow$ language acquisition), we additionally condition on rural areas as control for both paths, and we respectively condition on course visits for path 4 and on contact for path 5 .

\subsection{Summary Statistics}

TABLE 1 illustrates weighted summary statistics on most relevant variables included in later analyses based on our analytic sample comprising 13,187 observations. Summary statistics are differentiated by our main independent variable (i.e. whether refugees live in either rural or urban areas). Overall, most factors seem relatively balanced across regions which highlights the importance of administrative distribution measures, discussed in section 1. Nevertheless, some minor differences can be noticed.

301 Thus, refugees living in rural areas are younger (30.5 vs. 31.3, p < 0.05), less likely to be highlyeducated $(18.6 \%$ vs. $21.8 \%, \mathrm{p}<0.05)$ or from Syria $(35.3 \%$ vs. $44.2 \%, \mathrm{p}<0.05)$. 
306 Regarding our main theoretical variables, there is no significant difference in German language skills 307 between rural and urban locations. Frequent contact to Germans is significantly more likely in rural

308 areas and at the same time, any language course participation and specifically official course 309 participation is less likely for respondents in rural areas while unofficial course visits are slightly more 310 likely.

\section{Results}

\section{$314 \quad 4.1 \quad$ Main models}

$315 \quad$ Figure 3

316 illustrates average treatment effects of all hypothesized pathways for the causal effect of rural location 317 on refugees' language acquisition. Strikingly, there is only a comparatively small negative total effect 318 from living in rural areas on language skills, which is also not statistically significant.

319 For path 2 going from rural location to course participation, the picture is heterogeneous: considering

320 all courses combined, there is a very small insignificant effect suggesting that that refugees in rural 321 areas do not have lower access to language courses compared to more urban areas. However, when we 322 disaggregate the type of course, a different picture emerges. Living in a rural location reduces access

323 to formal federally-organized (BAMF) courses by about 3.2 percentage points $(\mathrm{p}<0.05)$ while course 324 participation in other non-BAMF courses tends to be more likely in rural areas by 2.3 percentage points 325 (ns). This may suggest that local communities offer their own language course support, perhaps partly 326 because centrally organized courses are less accessible in rural areas.

328 Rural location has significantly positive effects on refugees' contact with Germans (path 3): frequent 329 intergroup interactions (several times per week or daily) 4.6 percentage points more likely compared 330 to refugees' living in urban areas. This may demonstrate altered opportunity structures with regards to 331 intergroup contact across regions. Furthermore, the presence of contact has strong effects on refugees' 332 language skills (path 4): refugees reporting more contact with Germany show a significant increase of 


\section{Is there a rural penalty in language acquisition?}

3330.097 scale-points in language evaluation as compared to refugees who do not report it. Last, the

334 participation in language courses has significantly and strong positive effects on language skills for all

335 forms of courses. The strongest effects are present for the combined specification of course

336 participations with +0.085 scale points in language skills $(0-1)$, followed by official courses $(+0.069)$

337 and unofficial courses $(+0.043) .^{3}$

\section{$338 \quad 4.2 \quad$ Further analyses \& robustness checks}

\section{4.2.1 Measurements}

340 While the main analyses distinguished between different types of courses, it is also conceivable that

341 contact with Germans differs in frequency and effect on language acquisition depending on whether

342 the contact takes place at work, among friends, or in the neighborhood. Thus, some forms of contact

343 may occur relatively frequently, but the intensity of interaction and the depth of possible topics of

344 conversation may remain relatively superficial. The refugee sample does not distinguish between

345 contact with Germans in different spheres of life until the start of the second wave. Figure A1 therefore

346 presents the results for this reduced sample from wave 2 onward (8,703 cases). Specifically, the sample

347 includes information on contact with German friends, German neighbors and German colleagues

348 (including class mates at school/university) (SOEP Group 2020). Regarding the effect of a rural place

349 of living on these contact forms, there are no substantial differences visible between contact forms. All

350 forms of contact except those with German friends are significantly positively affected. This may

351 suggest that making friends is to some extent generally a greater hurdle than establishing other forms

352 of contacts. ${ }^{4}$ When friendships with Germans could be established, however, these have a particularly

353 strong effect on language skills and clearly outperform potentially more casual contacts such as those

354 with neighbors. Contacts with Germans at work, school or university also have relatively strong effects

355 on language acquisition (Figure A1).

\footnotetext{
${ }^{3}$ One reason may be the circumstance that this variable also includes relative advanced course forms like language courses preparing participants immediately prior to labor market entry. E.g. about $8 \%$ reporting any course visit, report (among others) the "ESF-BAMF" course for occupational language training.

${ }^{4}$ In the SOEP data, contact with German friends is about $20 \%$ reduced as compared to contact with Germans in general.
} 
356 Self-assessments of language skills are controversial with regards to their strengths in reflecting

357 objective language skills (Edele et al. 2015). Studies that have directly compared subjective language

358 assessments of second languages with objective language tests conclude that subjectively assessed

359 language proficiency is relatively accurate when objective levels of proficiency (i.e. levels that would

360 be identified by generalized tests) are either low or high (Ma and Winke 2019). However, in the process

361 of language learning from low to intermediate proficiency, the complexity in dealing with the language

362 increases, while at the same time it is not yet fully apparent how far the path to very good proficiency

363 actually still is. This can lead to misjudgments, especially in the case of intermediate skills, tending to

364 take the form of an underestimation of one's own language skills (Edele et al. 2015; Ma and Winke

365 2019). Thus, we run further robustness checks using interviewers' evaluation on respondents' German

366 skills which are also available in the data (Figure A2). We re-run all models from main analyses for

367 paths in which language-skills are involved. The overall path from rurality to language acquisition is

368 not significant in the interviewer estimate, as in the main models. Interestingly, as effects are measured

369 by interviewer assessment, courses have smaller effects on language skills and contact with Germans

370 has stronger effects on language skills. One interpretation of slight deviations from main results is that

371 language acquisition via social contacts may take place more subconsciously than that in language

372 courses, where an explicit confrontation with the foreign language takes place. Language skills gained

373 through social contacts may be less strongly expressed in a change in self-assessment relative to skills

374 gained through course attendance as refugees made a deliberate effort to improve their language skills

375 by attending a course which may lead them to overestimate their skills to reduce cognitive dissonance.

376 Overall, this check may indicate that our analyses overestimate course effects and underestimate 377 contact effects.

\section{$378 \quad$ 4.2.2 Varying DAG assumptions}

379 As discussed in section 2, a path between the two moderators of intergroup contact (M1) and course

380 visits (M2) is plausible in both directions (see Figure 1). For our main analyses, we blocked this path

381 by controlling for the respective other variable when estimating effects on language acquisition (path

3824 and 5). In further analyses presented in Figure A3, we softened this restriction by not controlling for

383 the other variable. Strikingly, there are no major differences in effect sizes observable between both

384 model assumptions. This indicates that recruitment into courses via intergroup contacts is - if at all -

385 a minor pathway present in the data. The same is true for intergroup contact as a result of course visits.

\subsubsection{Risk of reverse causality}




\section{Is there a rural penalty in language acquisition?}

387 Another robustness check addresses issues of reverse causality. Our argument hinges on the assumption

388 that both contacts to Germans and participation in courses have positive effects on language acquisition

389 (paths 4 and 5). Our results confirm this assumption empirically. However, it is possible that better

390 language skills lead to more contacts to Germans and better access to courses rather than vice versa.

391 To assess this possibility, we run separate models (Figure A4), taking advantage of the panel-structure

392 of the SOEP by comparing 2-wave panels of treated individuals starting a course/contact vs. non-

393 treated. By using two-way FE-regressions on this 2-wave data structure, we achieve a clear before-

394 after estimation (Goodman-Bacon 2018; Allison 2009) mitigating the risk of reverse causality. The

395 results illustrate that the positive effects of course attendance and contacts on German language skills

396 are clearly visible also when explicitly modeling the temporal processes in which events occur.

\section{$397 \quad$ 4.2.4 Estimation}

398 As a final step, we check whether effect directions are sensible towards our chosen estimation approach 399 for obtaining ATE's. Therefore, as alternative to 'regression adjustment', we also provide estimates 400 using two more approaches: inverse-probability-weighting (IPW) and inverse-probability-weighting 401 regression adjustment (IPWRA). A side-by-side comparison is provided in Figure A5. Ultimately, all 402 methodological approaches yield very similar results, strengthening the claim that our demonstrated 403 associations are robust to different estimation procedures.

\section{Conclusion}

405 This study explored the potential disadvantage that asylum seekers and refugees may face in terms of 406 language acquisition when being allocated to rural areas after arriving in Germany (i.e. "rural penalty”).

407 We propose a causal model based on DAGs and established language learning models and test our 408 hypotheses using large survey data from Germany (SOEP Group 2020). We find that asylum seekers 409 and refugees in rural areas do not have lower language skills compared to urban contexts (null effect).

410 We find that asylum seekers and refugees in rural areas benefit from higher levels of interaction with 411 German speakers while the disadvantage in terms of access to structured language courses appears 412 minor. Overall, the results support a 'compensation effect' whereas migrants compensate small 413 disadvantages in terms of access to courses with higher exposure to Germans.

414 These results have implications both for academic and policy discussions. Germany received several 415 million asylum seekers since 2012. Migrants often came from war torn countries with - on average 416 lower educational backgrounds. Integrating asylum seekers and refugees into society and allowing for 
417 equal participation is a major challenge. Acquiring the German language is key to integration and the

418 largest area of public investment by the government. In this context, it is striking that the evidence on

419 how local contexts influence integration outcomes is severely limited despite much debate regarding

420 the issue. Rather than testing very narrow hypotheses, our approach allowed us to study how various

421 mechanisms may offset each other within a more comprehensive causal model of language acquisition.

422 Our findings are consistent with previous literature in the sense that we find large positive effects of 423 both contacts to Germans and participation in language courses on language acquisition. However, we

424 show that these mechanisms are more or less pronounced depending on the local context.

425 The policy debate often centers on the allocation scheme of asylum seekers in Germany (Königstein 426 key) and the degree to which it produces winners and losers in terms of integration. We find that rural 427 areas do not necessarily disadvantage migrants in terms of language acquisition. This finding is 428 important as allocation of migrants to rural areas has been discussed in the context of reviving areas 429 suffering from demographic decline. The results also suggest that policymakers can further promote 430 language acquisition of asylum seekers and refugees by improving access formal government language 431 courses in rural areas and by facilitating interaction with Germans in urban areas.

432 The study faced two main limitations. First, our findings are based on observational data which limits 433 the approach to establish causality. However, we attempted to make our causal assumptions explicit 434 using DAGs. To further strengthen our causal claims, we benefit from the allocation policy in Germany 435 which randomly allocates asylum seekers across regions mirroring a natural experiment. In the 436 supplementary material, we also address reverse causality issues using panel fixed effects models. 437 Second, the data only contains few years since asylum seekers arrived in Germany. Future research 438 should study the long-term effects of being allocated to rural areas on language acquisition. In addition, 439 we encourage further research to explore "rural penalties" with respect to other relevant integration 440 outcomes such as employment, education, health, social exclusion and life satisfaction.

441 Despite these limitations, this study offers a comprehensive view of different pathways of language 442 acquisition among asylum seekers and refugees and how they may differ between rural and more urban 443 areas. 
Is there a rural penalty in language acquisition?

\section{References}

448

449

450

451

452

453

454

455

456

457

458

459

460

461

462

463

464

465

466

467

468

469

470

471

472

473

474

475

476

477

478

479

480

481

482

483

484

485

486
Aksoy, Cevat G., Panu Poutvaara, and Felicitas Schikora. 2020. First Time Around: Local Conditions and Multi-Dimensional Integration of Refugees: Center for Open Science.

Alba, Richard, Jennifer Sloan, and Jessica Sperling. 2011. "The Integration Imperative: The Children of Low-Status Immigrants in the Schools of Wealthy Societies." Annu. Rev. Sociol. 37 (1): 395 415. doi:10.1146/annurev-soc-081309-150219.

Arendt, Jacob N., Iben Bolvig, Mette Foged, Linea Hasager, and Giovanni Peri. 2020. "Language Training and Refugees' Integration.”.

Åslund, Olof, and Dan-Olof Rooth. 2007. "Do When and Where Matter? Initial Labour Market Conditions and Immigrant Earnings.” The Economic Journal 117 (518): 422-48. doi:10.1111/j.1468-0297.2007.02024.x.

Auer, Daniel. 2018. "Language Roulette - the Effect of Random Placement on Refugees' Labour Market Integration.” Journal of Ethnic and Migration Studies 44 (3): 341-62. doi:10.1080/1369183X.2017.1304208.

Bansak, Kirk, Jeremy Ferwerda, Jens Hainmueller, Andrea Dillon, Dominik Hangartner, Duncan Lawrence, and Jeremy Weinstein. 2018. "Improving Refugee Integration Through Data-Driven Algorithmic Assignment.” Science 359 (6373): 325-29. doi:10.1126/science.aao4408.

Bauer, Thomas, Gil S. Epstein, and Ira N. Gang. 2005. "Enclaves, Language, and the Location Choice of Migrants." J Popul Econ 18 (4): 649-62. doi:10.1007/s00148-005-0009-z.

Beaman, Lori A. 2012. "Social Networks and the Dynamics of Labour Market Outcomes: Evidence from Refugees Resettled in the U.S.” The Review of Economic Studies 79 (1): 128-61. doi:10.1093/restud/rdr017.

Beauftragte der Bundesregierung für Migration, Flüchtlinge und Integration. 2021. "Integration in Deutschland: Erster Bericht Zum Indikatorgestützten Integrationsmonitoring.” https://www.integrationsbeauftragte.de/resource/blob/1872554/1881534/91dd9a36d492ca4ba2948 2072473fa62/bericht-integrationsmonitoring-data.pdf.

Braun, Sebastian T., and Nadja Dwenger. 2020. "Settlement Location Shapes the Integration of Forced Migrants: Evidence from Post-War Germany." Explorations in Economic History 77:101330. doi:10.1016/j.eeh.2020.101330.

Brell, Courtney, Christian Dustmann, and Ian Preston. 2020. "The Labor Market Integration of Refugee Migrants in High-Income Countries.” Journal of Economic Perspectives 34 (1): 94-121. doi:10.1257/jep.34.1.94.

Brücker, Herbert, Philipp Jaschke, and Yuliya Kosyakova. 2019. Integrating Refugees and Asylum Seekers into the German Economy and Society: Empirical Evidence and Policy Objectives. Washington, D.C. https://cdn.givingcompass.org/wpcontent/uploads/2019/12/18123415/tcm_2019_germany-final.pdf.

Brücker, Herbert, Nina Rother, and Jürgen Schupp. 2017. "IAB-BAMF-SOEP-Befragung Von Geflüchteten 2016: Studiendesign, Feldergebnisse Sowie Analysen Zu Schulischer Wie Beruflicher Qualifikation, Sprachkenntnissen Sowie Kognitiven Potenzialen.” IAB Forschungsbericht 13. https://doku.iab.de/forschungsbericht/2017/fb1317.pdf. 
487

488

489

490

491

492

493

494

495

496

497

498

499

500

501

502

503

504

505

506

507

508

509

510

511

512

513

514

515

516

517

518

519

520

521

522

523

524

525

526

527
Chiswick, B. R., and P. W. Miller. 1996. "Ethnic Networks and Language Proficiency Among Immigrants." J Popul Econ 9 (1): 19-35. doi:10.1007/PL00013277. . 2001. "A Model of Destination-Language Acquisition: Application to Male Immigrants in Canada." Demography 38 (3): 391-409. doi:10.1353/dem.2001.0025.

Chiswick, Barry R., and Paul W. Miller. 2002. "Immigrant Earnings: Language Skills, Linguistic Concentrations and the Business Cycle." J Popul Econ 15 (1): 31-57. doi:10.1007/PL00003838.

Chiswick, B. R., \& Wang, Z. 2019. Social Contacts, Dutch Language Proficiency and Immigrant Economic Performance in the Netherlands (419th ed. GLO Discussion Paper.

Clausen, Jens, Eskil Heinesen, Hans Hummelgaard, Leif Husted, and Michael Rosholm. 2009. "The Effect of Integration Policies on the Time Until Regular Employment of Newly Arrived Immigrants: Evidence from Denmark." Labour Economics 16 (4): 409-17. doi:10.1016/j.labeco.2008.12.006.

Danzer, Alexander M., and Firat Yaman. 2013. "Do Ethnic Enclaves Impede Immigrants' Integration? Evidence from a Quasi-Experimental Social-Interaction Approach." Review of International Economics 21 (2): 311-25. doi:10.1111/roie.12038.

Dustmann, Christian, Francesco Fasani, Tommaso Frattini, Luigi Minale, and Uta Schönberg. 2017. "On the Economics and Politics of Refugee Migration." Economic Policy 32 (91): 497-550. doi:10.1093/epolic/eix008.

Edin, P.-A., P. Fredriksson, and O. Aslund. 2003. "Ethnic Enclaves and the Economic Success of Immigrants--Evidence from a Natural Experiment." The Quarterly Journal of Economics 118 (1): 329-57. doi:10.1162/00335530360535225.

Einig, Klaus. 2015. “Gewährleisten Zentrale-Orte-Konzepte Gleichwertige Lebensverhältnisse Bei Der Daseinsvorsorge?” Informationen zur Raumentwicklung 1.

Elwert, Felix. 2013. "Graphical Causal Models.” In Handbook of Causal Analysis for Social Research, edited by Stephen L. Morgan, 245-73. Handbooks of Sociology and Social Research. Dordrecht: Springer Netherlands.

Espenshade, Thomas J., and Haishan Fu. 1997. “An Analysis of English-Language Proficiency Among U.S. Immigrants.” Am Sociol Rev 62 (2): 288. doi:10.2307/2657305.

Esser, Hartmut. 2006. Sprache Und Integration: Die Sozialen Bedingungen Und Folgen. Frankfurt/Main, New York: Campus.

Fachkommission Integrationsfähigkeit. 2021. Shaping Our Immigration Society Together. Report of the Federal Government Expert Commission on the Framework for Sustainable Integration. Berlin.

Godøy, Anna. 2017. "Local Labor Markets and Earnings of Refugee Immigrants." Empir Econ 52 (1): 31-58. doi:10.1007/s00181-016-1067-7.

Heath, Anthony F., Catherine Rothon, and Elina Kilpi. 2008. "The Second Generation in Western Europe: Education, Unemployment, and Occupational Attainment." Annu. Rev. Sociol. 34 (1): 211-35. doi:10.1146/annurev.soc.34.040507.134728.

Hoehne, Jutta, and Ines Michalowski. 2016. "Long-Term Effects of Language Course Timing on Language Acquisition and Social Contacts: Turkish and Moroccan Immigrants in Western Europe.” International Migration Review 50 (1): 133-62. doi:10.1111/imre.12130. 


\section{Is there a rural penalty in language acquisition?}

Kaida, Lisa. 2013. "Do Host Country Education and Language Training Help Recent Immigrants Exit Poverty?” Social Science Research 42 (3): 726-41. doi:10.1016/j.ssresearch.2013.01.004.

Kanas, Agnieszka, Barry R. Chiswick, Tanja van der Lippe, and Frank van Tubergen. 2012. "Social Contacts and the Economic Performance of Immigrants: A Panel Study of Immigrants in Germany." International Migration Review 46 (3): 680-709. doi:10.1111/j.17477379.2012.00901.x.

Kosyakova, Yuliya, and Hanna Brenzel. 2020. "The Role of Length of Asylum Procedure and Legal Status in the Labour Market Integration of Refugees in Germany." SozW 71 (1-2): 123-59. doi:10.5771/0038-6073-2020-1-2-123.

Kosyakova, Yuliya, Cornelia Kristen, and Christoph Spörlein. 2021. "The Dynamics of Recent Refugees' Language Acquisition: How Do Their Pathways Compare to Those of Other New Immigrants?" Journal of Ethnic and Migration Studies, 1-24. doi:10.1080/1369183X.2021.1988845.

Kristen, Cornelia, Peter Mühlau, and Diana Schacht. 2016. "Language Acquisition of Recently Arrived Immigrants in England, Germany, Ireland, and the Netherlands." Ethnicities 16 (2): 180212. doi:10.1177/1468796815616157.

Küpper, Patrick. 2020. "Was Sind Eigentlich Ländliche Räume.” In Ländliche Räume, edited by Bundesinstitut für politische Bildung, 4-7. Informationen zur politischen Bildung 343.

Liebig, Stefan, Herbert Brücker, Renate Leistner-Rocca, Jan Goebel, Markus M. Grabka, Nina Rother, Carsten Schröder et al. 2021. "IAB-BAMF-SOEP-Befragung Geflüchteter 2019.”.

Lochmann, Alexia, Hillel Rapoport, and Biagio Speciale. 2019. "The Effect of Language Training on Immigrants' Economic Integration: Empirical Evidence from France." European Economic Review 113:265-96. doi:10.1016/j.euroecorev.2019.01.008.

Martén, Linna, Jens Hainmueller, and Dominik Hangartner. 2019. "Ethnic Networks Can Foster the Economic Integration of Refugees." Proceedings of the National Academy of Sciences of the United States of America 116 (33): 16280-85. doi:10.1073/pnas.1820345116.

Martinovic, B., F. van Tubergen, and I. Maas. 2009. “Dynamics of Interethnic Contact: A Panel Study of Immigrants in the Netherlands." European Sociological Review 25 (3): 303-18. doi:10.1093/esr/jen049.

Morgan, Stephen L., and Christopher Winship. 2014. Counterfactuals and Causal Inference. Cambridge: Cambridge University Press.

Ohlinger, Rainer, and Raphaela Schweiger. 2019. Integrationskursangebote in Ländlichen Räumen Stärken: Differenzierte Angebote Ermöglichen - Flexibilität Erhöhen. Stuttgart: Robert Bosch Stiftung.

Rösch, Tabea, Hanne Schneider, Johannes Weber, and Susanne Worbs. 2020. Integration Von Geflüchteten in Ländlichen Räumen. 36th ed. Forchungsbericht. Nürnberg: BAMF.

Sarvimäki, Matti, and Kari Hämäläinen. 2016. "Integrating Immigrants: The Impact of Restructuring Active Labor Market Programs." Journal of Labor Economics 34 (2): 479-508. doi:10.1086/683667.

Schader Stiftung. 2011. Erfolgreiche Integrationim Ländlichen Raum: Handlungsempfehlungen Und Gute-Praxis-Beispiele. 
569 Scheible, Jana, and Hanne Schneider. 2020. Deutsch Lernen Auf Dem Land:

$570 \quad$ Handlungsempfehlungen Für Die Sprachförderung Von Migrantinnen Und Migranten in 571 Deutschland. 7 vols. Berlin: FES.

572 SOEP Group. 2020. "SOEP-Core - 2018: Individual and Biography M3-M5, Initial Interview, with 573 Reference to Variables.” SOEP Survey Papers 814.

574 Tissot, Anna, Johannes Croisier, Giuseppe Pietrantuono, Andreea Baier, Lars Ninke, Nina Rother, 575 and Christian B. von Gostomski. 2019. Zwischenbericht I Zum Forschungsprojekt „Evaluation 576 Der Integrationskurse (EvIk) “: Erste Analysen Und Erkenntnisse. Forschungsbericht 33.

577 van Tubergen, F. 2010. "Determinants of Second Language Proficiency Among Refugees in the 578 Netherlands.” Social Forces 89 (2): 515-34. doi:10.1353/sof.2010.0092.

579 Vroome, Thomas de, and Frank van Tubergen. 2010. "The Employment Experience of Refugees in 580 the Netherlands." International Migration Review. 


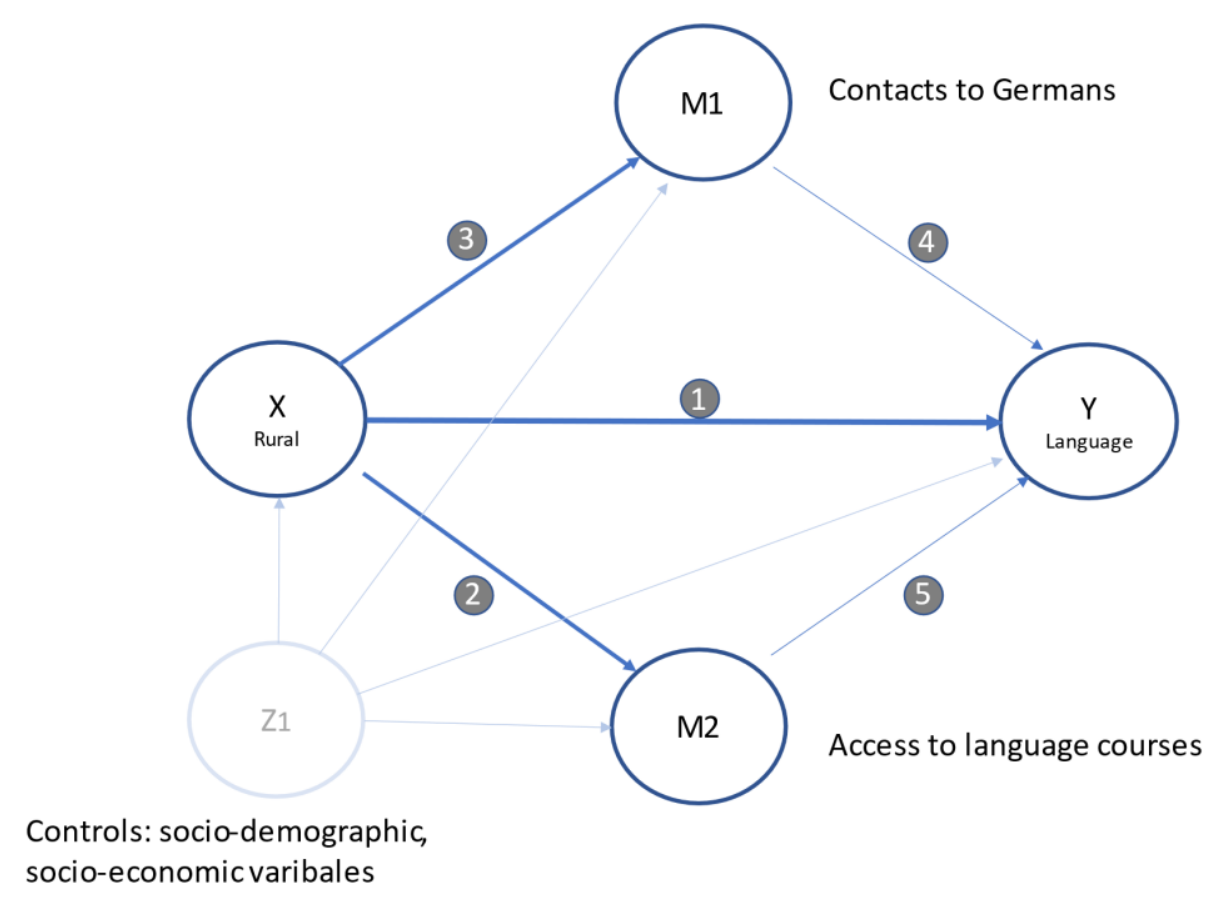

FIGURE 1 | Directed Acyclic Graph of the proposed causal model 

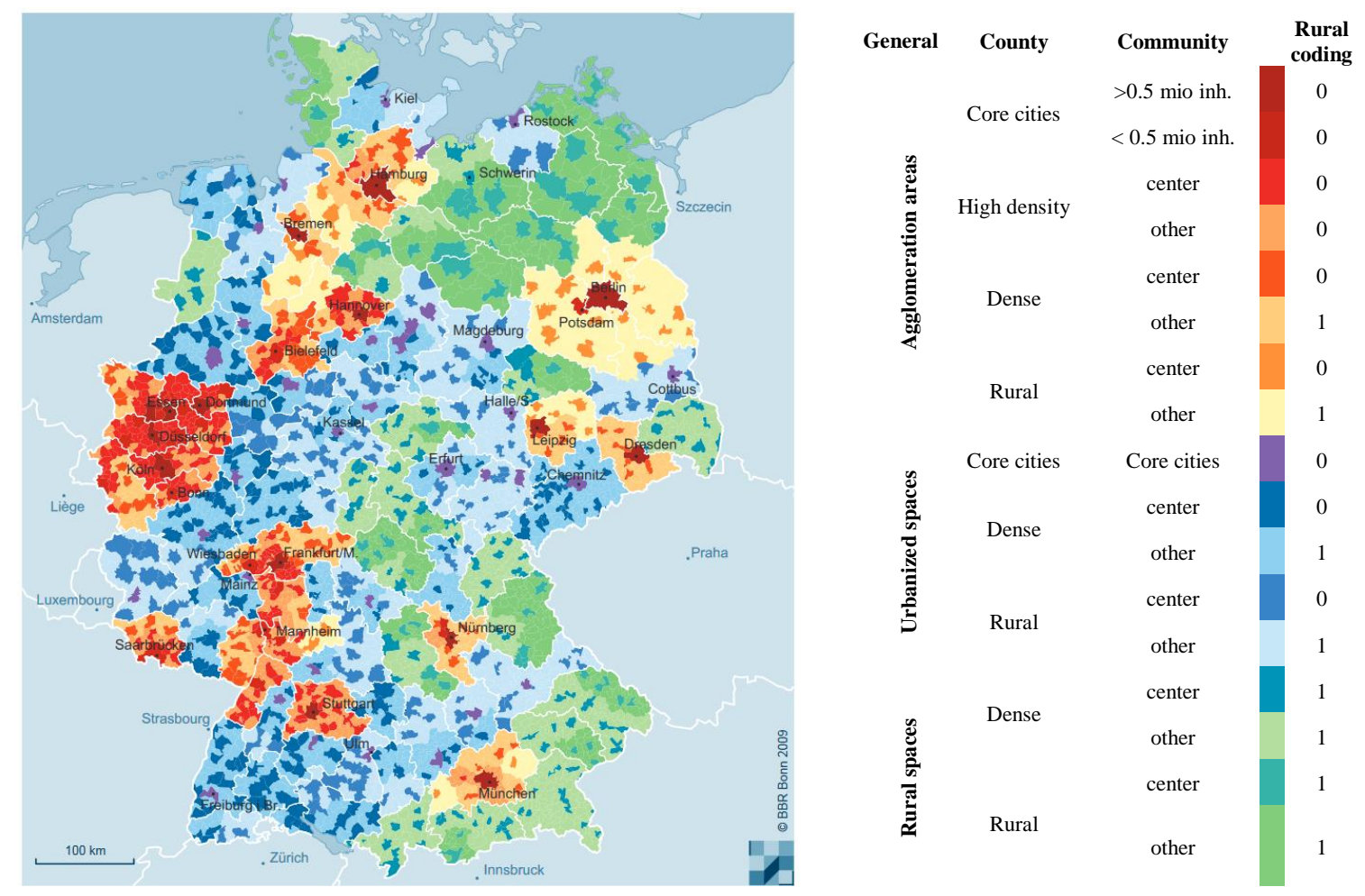

FIGURE 2 | Regional classifications available in SOEP data

Displayed are the 17 residential-structural community types in Germany, introduced by the Federal Institute for Research on Building, Urban Affairs and Spatial Development and available within scientific-use files for SOEP-surveys with regards to their place of residence. Figure adopted from BBR (2009). 
(a) Path-model

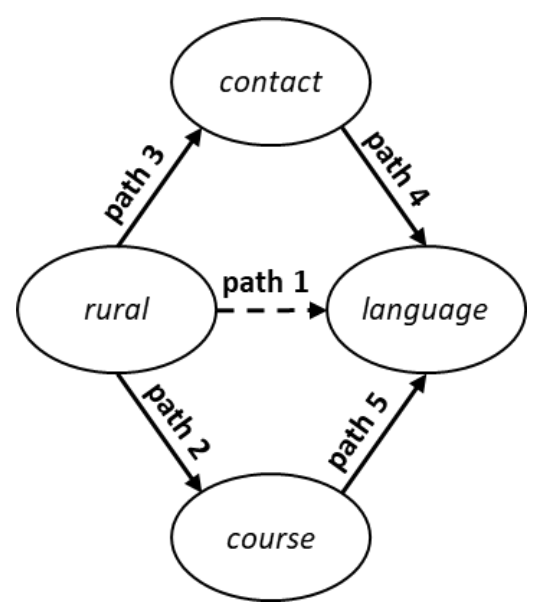

(b) Treatment effect estimations

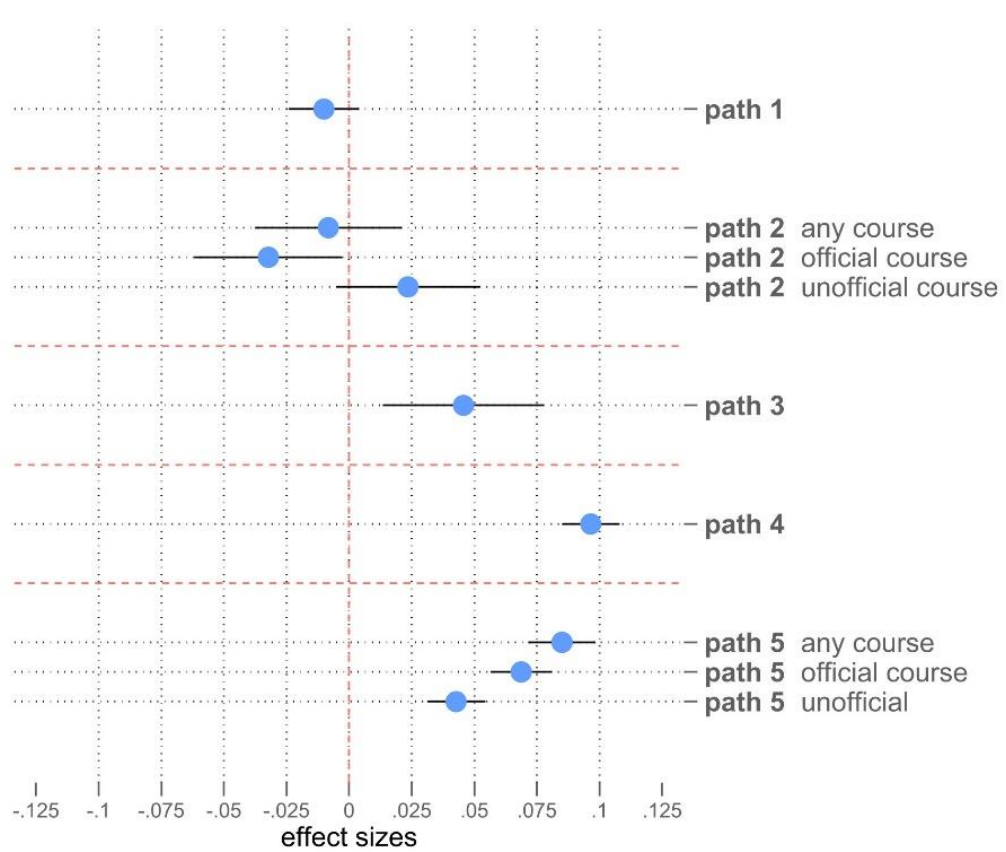

FIGURE 3 | A model for rural language acquisition - Treatment Effect Estimations

Panel (a) displays the theoretical model described in detail in section 2, panel (b) shows average treatment effects (ATE) treatment effect coefficients with their 95-\% confidence-intervals resulting from 9 separate regressions using the regression adjustment method (including population weights). Outcomes are all scaled as binary (0-1), language-proficiency is scaled as an index taking values between 0 and 1 (path $1,4,5$ ). Non-displayed controls are included for respondents' sex, age, educational-levels, number of children, country of birth, years since immigration, legal status, partnership status and moving indicator. $\mathrm{N}=13,187$ observations. 
593 TABLE 1 | Summary Statistics.

\begin{tabular}{|c|c|c|c|c|c|c|c|c|c|}
\hline \multirow[b]{2}{*}{ Variable } & \multirow[b]{2}{*}{ Group } & \multicolumn{4}{|c|}{ Urban areas } & \multicolumn{4}{|c|}{ Rural areas } \\
\hline & & MEAN & SD & MIN & MAX & MEAN & SD & MIN & MAX \\
\hline Female & & 0.277 & 0.447 & 0 & 1 & 0.264 & 0.441 & 0 & 1 \\
\hline Age & & 31.290 & 10.687 & 17 & 97 & 30.494 & 9.690 & 17 & 79 \\
\hline In relationship & & 0.366 & 0.482 & 0 & 1 & 0.351 & 0.477 & 0 & 1 \\
\hline Years since Immigration & & 2.153 & 1.015 & 0 & 5 & 2.071 & 0.999 & 0 & 5 \\
\hline Number of children & & 1.167 & 1.766 & 0 & 15 & 1.144 & 1.742 & 0 & 19 \\
\hline \multirow[t]{3}{*}{ Educational attainment } & Low & 0.387 & 0.487 & 0 & 1 & 0.411 & 0.492 & 0 & 1 \\
\hline & Middle & 0.395 & 0.489 & 0 & 1 & 0.403 & 0.491 & 0 & 1 \\
\hline & High & 0.218 & 0.413 & 0 & 1 & 0.186 & 0.390 & 0 & 1 \\
\hline \multirow[t]{5}{*}{ Country of birth } & Syria & 0.442 & 0.497 & 0 & 1 & 0.353 & 0.478 & 0 & 1 \\
\hline & Iraque & 0.089 & 0.284 & 0 & 1 & 0.089 & 0.284 & 0 & 1 \\
\hline & Afghan. & 0.118 & 0.323 & 0 & 1 & 0.148 & 0.355 & 0 & 1 \\
\hline & Eritrea & 0.048 & 0.213 & 0 & 1 & 0.054 & 0.226 & 0 & 1 \\
\hline & Other & 0.303 & 0.460 & 0 & 1 & 0.357 & 0.479 & 0 & 1 \\
\hline \multirow{4}{*}{$\begin{array}{r}\text { German language skills } \\
\text { Course visit }\end{array}$} & & 0.495 & 0.254 & 0 & 1 & 0.469 & 0.249 & 0 & 1 \\
\hline & official & 0.438 & 0.496 & 0 & 1 & 0.380 & 0.500 & 0 & 1 \\
\hline & inofficial & 0.312 & 0.496 & 0 & 1 & 0.342 & 0.486 & 0 & 1 \\
\hline & any & 0.691 & 0.463 & 0 & 1 & 0.673 & 0.474 & 0 & 1 \\
\hline
\end{tabular}

Displayed are weighted summary statistics for refugees living either in regional centers $\left(n_{\text {prs-years }}=9,261\right)$ or in rural area $\left(n_{\text {prs-years }}=3,926\right)$. 